\title{
Ferritin nanocages: a biological platform for drug delivery, imaging and
}

\section{theranostics in cancer}

Marta Truffi, ${ }^{a}$ Luisa Fiandra, ${ }^{a}$ Luca Sorrentino, ${ }^{a, b}$ Matteo Monieri, ${ }^{a}$ Fabio Corsi, ${ }^{a, b}$ Serena Mazzucchelli $^{a{ }^{*}}$

a Laboratory of Nanomedicine, Department of Biomedical and Clinical Sciences University of Milan, “Luigi Sacco” Hospital, Via G. B. Grassi, 74, 20157 Milano, Italy

b Surgery Division, Department of Biomedical and Clinical Sciences University of Milan, "Luigi Sacco" Hospital, Via G. B. Grassi, 74, 20157 Milano, Italy

*serena.mazzucchelli@gmail.com; Tel. +3902390440450

KEYWORDS: protein-based nanocages, ferritin, drug delivery, imaging, cancer.

\section{Abstract}

Nowadays cancer represents a prominent challenge in clinics. Main achievements in cancer management would be the development of highly accurate and specific diagnostic tools for early detection of cancer onset, and the generation of smart drug delivery systems for targeted chemotherapy release in cancer cells. In this context, protein-based nanocages hold a tremendous potential as devices for theranostics purposes. In particular, ferritin has emerged as an excellent and promising proteinbased nanocage thanks to its unique architecture, surface properties and high biocompatibility. By exploiting natural recognition of the Transferrin Receptor 1, which is overexpressed on tumor cells, ferritin nanocages may ensure a proper drug delivery and release. Moreover, researchers have applied surface functionalities on ferritin cages for further providing active tumor targeting. Encapsulation strategies of non metal-containing drugs within ferritin cages have been explored and successfully performed with encouraging results. Various preclinical studies have demonstrated that 
nanoformulation within ferritin nanocages significantly improved targeted therapy and accurate imaging of cancer cells. Aims of this review are to describe structure and functions of ferritin nanocages, and to provide an overview about the nanotechnological approaches implemented for applying them to cancer diagnosis and treatment.

\section{Introduction}

Cancer is a leading cause of death worldwide, accounting for 8.2 million deaths in 2012 [1]. A main goal of current cancer research is early recognition of cancer cells and selective treatment, before the cancer can progress to an unfavourable stage. Based on this rationale, the aim of several modern therapeutic approaches for cancer is to selectively remove the tumor before it evolves into its superior stages, and the eventual onset of metastases. For this scenario to be successful there is a growing need to develop: 1) novel and more sensitive diagnostic tools to improve screening accuracy and the detection rate of malignancies, staging and follow up settings, and to achieve less extensive surgery or medical therapy; 2) new drug formulations with enhanced efficacy toward cancer cells and reduced toxicity toward healthy cells [2].

Nanotechnology holds great clinical potential in reaching these major goals and a number of nanodevices have been designed to specifically target cancer cells. These nanodevices can be loaded with different kinds of chemotherapeutics and/or contrast agents, and provide unmatched promise for development of theranostic devices for both cancer diagnosis and treatment. Indeed, nanoparticles have demonstrated their potential to solve crucial issues involving bioavailability, tissue penetration and circulation time [3]. Several nanoparticles constructed from metals, semi-conductors or polymers, have been tested in preclinical studies [4], but only a few of them have been clinically approved due to their toxicity, immunogenicity and sequestration by the reticulo-endothelial system [5]. Therefore, much effort has been directed into the design and synthesis of chemically engineered nanostructures that are biologically compatible. 
Naturally occurring nanoparticles have existed for millions of years, and they include a wide variety of nanostructures, which may be formed by inorganic (i.e. magnetosomes) or organic materials. These nanoparticles can be intracellular or extracellular and may have different biological roles [6]. Despite these differences, natural nanoparticles are charming from the biomedical point of view due to their uniform structure, low toxicity, and ability to evade the immune system. Moreover, they are easily degraded after fulfilling their function $[6,7]$. These features place them ahead of inorganic or synthetic materials in clinical translation [7]. Biological nanoparticles are assembled from molecules or atoms synthesized in a biological system with sizes ranging from 1 to $100 \mathrm{~nm}$. They include magnetosomes, lipoproteins, viruses, exosomes and ferritins [6].

Magnetosomes are specialized organelles with narrow size (50-70 $\mathrm{nm}$ in diameter), uniform morphology and low toxicity; they have evolved from magnetotactic bacteria and are composed of a lipid bilayer surrounding magnetic iron-containing minerals [8-10]. Lipoproteins are self-assembling structures that contain phospholipids, non-esterified cholesterol and specialized proteins, forming a spherical or discoidal shell (from 7 to $>80 \mathrm{~nm}$ ), which surrounds a core of non-polar lipids, triacylglycerols and esterified cholesterols $[11,12]$. Exosomes are nanometer-sized structures secreted by cells and consist of an external lipid bilayer, which offers a non-immunogenic and non-toxic mechanism for the delivery of targeted proteins or nucleic acids, protecting them from degradation and macrophage endocytosis [1316]. Viruses and virus-like particles may also be considered to be biological nanoparticles. They include a wide variety of sizes and morphologies with defined geometries, uniform shape and a robust protein shell. They are suitable for chemical- and bio-conjugation. Although their capsids are stable over a wide range of $\mathrm{pH}$ and temperatures, they are difficult to produce in bulk, and this represents a severe limitation for their use in nanotechnology [17].

Among all classes of biological nanoparticles here we focus on ferritins, which are iron storage and transport proteins found in most living organisms [18]. Recombinant ferritin provides a central cavity, which can be efficiently loaded with transition metals, drugs, fluorescent molecules or contrast agents 
$[19,20]$. Since it has a uniform cage, ferritin allows the precise control of the amount of encapsulated molecules, which is a critical feature in defining drug dosage. Moreover, the protein shell of ferritins can be easily modified either chemically or genetically to introduce different functionalities [21, 22]. All of these attributes highlight ferritin and its derivatives as powerful systems with potential application in nanomedicine. Indeed, they have been investigated as a novel type of nano-platform for imaging and drug delivery in cancer $[19,23]$. The aim of this review is to describe recent findings about ferritin nanocages' structure and function, and their biotechnological and biomedical applications for MRI, optical imaging and drug delivery in cancer. An overview of strategies used for ferritin surface modification to obtain formulations suitable for different clinical uses will be also provided.

\section{Ferritin nanocages: structure and physiological role}

Ferritin is probably the most studied protein after hemoglobin. It has been investigated since 1937, when Laufberger described its purification with Cadmium salts [24], and over the last decade it has attracted the interest of many nanotechnologists due to its properties [25]. It is a ubiquitous protein found in eubacteria, archea, plants and animals, but not in yeast [25]. Ferritin exists in extracellular and intracellular compartments, such as the cytosol, nucleus and mitochondria and its main roles are iron storage and homeostasis [26]. Therefore, it is one of the most highly conserved molecules.

Ferritin is a large protein of $450 \mathrm{kDa}$ composed of 24 subunits that self-assemble into a spherical cagelike structure with inner and outer dimensions of 8 and $12 \mathrm{~nm}$, respectively. Eukaryotes have two ferritin genes encoding the heavy $(\mathrm{H} ; 21 \mathrm{kDa})$ and the light $(\mathrm{L} ; 19 \mathrm{kDa})$ chains. The H-chain is responsible for the oxidation of $\mathrm{Fe}$ (II) to $\mathrm{Fe}(\mathrm{III})$ and includes the ferroxidase catalytic site, while the L-chain plays a role in iron nucleation [27]. $\mathrm{H}$ and $\mathrm{L}$ chains co-assemble into a 24-mer heteropolymer, where the H-chain to L-chain ratio varies according to a tissue specific distribution [25]. Ferritin protects cells from the damage caused by the Fenton reaction during oxidative stress, by sequestering $\mathrm{Fe}^{2+}$, a source of toxic

reactive oxygen species, and converting it into harmless $\mathrm{Fe}^{3+}$, which is stored as ferrihydrite crystals. The ferritin protein cage can accommodate up to 4500 iron atoms [25]. This protective action is crucial in the nucleus, where the DNA has to be particularly preserved from iron-induced oxidative damage 
[28]. Ferritin translocates into the nucleus through an ATP-dependent mechanism [28, 29], and Oglycosylation of the $\mathrm{H}$-chain seems to be involved in its nuclear translocation, but a Nuclear Localization Sequence (NLS) is not required [29]. However, it was not clear whether the integrity of ferritin was maintained during translocation. Recently, the Knez group has shed light on this issue by demonstrating that ferritin nanoparticles are intact during translocation [30].

The ferritin quaternary structure has eight hydrophilic channels that seem to mediate iron transit in and out of the protein cage. There are also six hydrophobic channels, which do not seem to be involved in iron exchange although they could mediate the transit of protons [31]. In spite of the structural rigidity of ferritins in the physiological environment, the protein cages can be reversibly disassembled when the $\mathrm{pH}$ becomes extremely acidic $(\mathrm{pH} 2-3)$ or basic $(\mathrm{pH} 10-12)[27,32]$. When the $\mathrm{pH}$ returns to neutrality ferritin monomers are able to self-assemble in a shape memory fashion. Moreover, the ferritin cage is resistant to denaturants, including heating to high temperatures $\left(>80{ }^{\circ} \mathrm{C}\right)[25]$.

Ferritin features have been extensively studied and implemented by researchers, thus allowing the use of ferritin nanocages as biological nanoparticles for nanomedical applications.

\section{Surface modification of ferritin nanoparticles and cellular interactions}

Extracellular ferritin interacts with cells through the receptor of transferrin 1 (TfR1), which was identified in 2010 by Seaman's group [33]. They demonstrated that TfR1 specifically binds H-ferritin, while L-ferritin shows low interaction. After binding on the cell surface, the H-ferritin-TfR1 complex is internalized, and can be found in early and recycling endosomes [33, 27], demonstrating that TfR1 coordinates the processing and the use of iron by binding both Transferrin and H-ferritin [34]. Hferritin is also able to interact with the T-cell Immunoglobulin and Mucin domain-2 (TIM-2) [35, 36], which is overexpressed in oligodendrocytes and B-cells [37, 38], and is internalized in endosomes upon binding [39]. Otherwise, L-ferritin binds to the Scavenger Receptor Class A, Member 5 (SCARA-5) [40], which is found in macrophages and the retina. Both $\mathrm{H}$ and $\mathrm{L}$ ferritin nanoparticles have been produced via DNA-recombinant technology. H-ferritin, which naturally interacts with the 
TfR1, are the most extensively studied [33]. By exploiting the TfR1 overexpression in many types of tumor cells, Fan and coworkers have developed a ferritin-based system for specifically visualizing tumors among normal cells and healthy tissues [41]. That study demonstrated that the intrinsic targeting of ferritin towards cancer cells could be used to design naturally targeted nanoparticles for theranostic purposes.

Despite the natural targeting of ferritin towards cancer cells, several research groups have modified the surface of ferritin nanocages by inserting a number of target motifs, such as antibodies, peptides and antibody fragments, in order to drive nanoparticles towards specific cells by selective recognition (Figure 1). Both lysines and cysteines on the ferritin surface have been exploited for chemical conjugation using different heterobifunctional cross-linkers with N-hydroxysuccinimide (NHS) ester and maleimide groups [42-44]. Lys and Cys residues have also been employed to chemically attach dyes, quencher molecules or polyethylene glycol (PEG) molecules [22, 45]. Most conjugation strategies have been designed and realized by genetically engineering ferritin monomers. Targeting moieties, such as the RGD peptide [46, 47], the anti-melanocyte stimulating hormone peptide [48, 45] or the extracellular domain of myelin oligodendrocyte glycoprotein (MOG) [49] have been expressed as N-terminal fusion proteins, allowing 24 targeting domains to be exposed on the ferritin cage surface, with uniform and precise orientation. In the last year, the surface conjugation of ferritin nanoparticles with a composite of four different peptides was reported. That was undertaken by Nterminal cloning four peptides onto the ferritin sequence: an enzymatically cleaved peptide (ECP) to release siRNA, a cationic peptide (CAP) to capture siRNA, a cell penetrating peptide (CPP) and a tumor cell targeting (CTP) moiety [50]. N-terminal fusion proteins have also been produced to display viral hemagglutinin on the ferritin surface, with the resulting neutralization of H1N1 viruses [51]. Alternatively, the production of ferritin nanoparticles with peptides fused at the C-terminal has been reported for the development of dendritic cell-based vaccines [52]. Beyond these strategies, other approaches for the conjugation of targeting moieties on ferritin surface have also been explored, including ferritin nanocage biotinylation in order to insert targeting functionalities [53], or the genetic 
engineering of ferritin for generating a fusion protein, which exploits $\mathrm{N}$-terminal protein $\mathrm{G}$ for antibody immobilization [54].

\section{Nanotechnological applications of ferritin}

Ferritin has attracted much interest due to its potential use as reaction chamber for the production of metal nanoparticles, or as a template for semi-conductor production [55]. Ferritin nanocages allow chemical synthesis to occur in restricted cavities with homogenous shape and atomic composition [56]. Ferritin nanocages have been extensively exploited for the biomineralization of metal oxides, such as iron [57], manganese [58], cobalt [59], chromium and nickel oxides [60]. Among the different protocols, the simplest and most suitable method of mass-production is the one-pot synthesis strategy developed by the Yamashita group [56], which developed metal-loaded ferritin nanocages with potential for nanoelectronical application [56].

Nanoparticles obtained from mineralization of semiconductors are very attractive from the nanotechnological point of view, since their fluorescence properties are closely related to nanoparticle size and shape [56]. In this context, ferritin nanocage cavities have been used for the synthesis of semi-conductor nanoparticles. However, the main drawback of this process is that ion aggregation is induced by high concentrations of $\mathrm{Cd}^{2+}$ or $\mathrm{Zn}^{2+}$ and $\mathrm{Se}^{2-}$ during the chemical reaction [56, 61], and because of this only a few research groups are engaged in its development $[56,61]$. The synthesis of $\mathrm{CdSe}$ and $\mathrm{ZnSe}$ using ferritins as a reaction chamber has been successfully obtained by Yamashita and coworkers, who have designed a new chemical approach called the Slow Chemical Reaction System $[62,63]$. This method avoids ion aggregation since $\mathrm{Cd}^{2+}$ or $\mathrm{Zn}^{2+}$ are attracted inside the apoferritin chamber by inner negative residues, thus preventing the aggregation process; therefore, mineralization inside an apoferritin cavity slows down the nucleation of CdSe or ZnSe [62-65].

\section{Potential of ferritin nanoparticles in cancer}

While ferritin nanoparticles have been widely investigated in the context of nanotechnology, their main application concerns the field of nanomedicine. Indeed, apart from their application in the 
development of vaccines [51,52], several research groups are engaged in the study of ferritin as imaging and drug delivery systems for the diagnosis and treatment of tumors, as summarized in Table 1.

\subsection{Ferritin nanoparticles as a drug delivery platform}

Their high stability, biocompatibility, ability to disassemble and reassemble in a shape memory fashion and disposition for surface modification make ferritin nanoparticles an ideal platform for drug delivery [55]. Indeed, in physiological conditions ferritin has a stable 24-mer cage architecture, while in highly acidic and basic conditions its quaternary structure disassembles, and then reassembles when the $\mathrm{pH}$ of the solution is brought to neutrality [66]. This feature has been used to encapsulate molecules in solution within ferritin cavities, simply by disassembling and reassembling the 24-mer architecture (Figure 2). Drugs with a natural tendency to bind metals, such as cisplatin and desferoxamine B [67], have been easily entrapped in the ferritin shell. Cisplatin encapsulation was first reported in 2007 by Gao and coworkers [68], who also studied the cellular uptake of these nanoparticles and several applications in tumor treatment [69]. The Huang group has used cisplatinloaded apoferritin to study, with a proteomic approach, the apoptotic process induced by nanoparticles in gastric cancer cells [70]. Moreover, a drug delivery device targeted to melanomas has been developed using cisplatin-loaded ferritin, chemically functionalized with an antibody against the melanoma antigen CSPG4 [42]. These studies have provided strong evidence of an enhanced efficacy of antiblastic therapy when it is encapsulated in ferritin-based nanoparticles, particularly in terms of targeting cancer cells such as melanoma, a type of cancer totally refractory to chemotherapy in later stages [42].

However, most of the currently used chemotherapies are not based on metals such as cisplatin, and the incorporation of non-metal-containing drugs within ferritin is complicated by their limited interaction with the protein cage. To overcome this drawback, different approaches have been evaluated, mainly focused on forming complexes of drugs with transition metals or the addition of charged accessory 
molecules [3, 71]. Doxorubicin (DOX) encapsulation in ferritin nanocages represents the most extensively investigated system for delivery of anticancer drugs [47]. DOX is a widely used cytotoxic drug for several types of solid tumors and has an excellent anticancer activity; however, its use is dose-limiting since it is associated with several major toxicities, when administered at high doses [47]. DOX pre-complexed with $\mathrm{Cu}(\mathrm{II})$ has been loaded inside ferritin nanocages and evaluated in vitro and in vivo in U87MG glioblastoma tumor models. Eighty percent of DOX was gradually released from RGD-functionalized apoferritin within 10 hours of incubation at $37{ }^{\circ} \mathrm{C}$ in phosphate buffered saline (PBS), while the copper remained bound to the internal surfaces of the nanocages. This targeted nanoformulation has increased drug tumor uptake and accumulation, tumor growth inhibition, circulation half-life, and has reduced the cardiotoxicity induced by free DOX [47]. Other groups have set up DOX loading strategies that do not involve complexes with transition metals. In these cases, good encapsulation efficiency has also been obtained [72, 73, 27], and excellent results in terms of tumor growth inhibition and reduced toxicity have been reported, both in vitro [27] and in vivo [73]. In vivo results clearly demonstrated that ferritin nanocages improve DOX bioavailability, tumor accumulation and clearance, and suggested that ferritin-mediated active targeting provides a major contribution (Figure 4) [73]. The mechanisms and kinetics of drug release from ferritin shell has not been completely elucidated, although reported data with DOX suggest that encapsulation is stable in serum and that a pH-triggered release takes place in vitro [75]. Moreover, the Knez group demonstrated that ferritin translocates into the nucleus mediating the nuclear release of DOX, while our group has hypothesized that DOX loaded ferritin acts as a Trojan horse because it has been translocated into the nucleus following DNA damage caused by the partial release in the cytoplasm of encapsulated DOX, by a self-triggered translocation mechanism which releases the drug directly into the nuclear compartment $[27,30]$.

In this context, the use of unfunctionalized ferritin seems to be advantageous for many reasons: 1) higher purification yield [72, 27]; 2) high tumor recognition [72] specific tumor recognition mediated by TfR1; 3) ferritin specific physiological behavior is not prevented, allowing the nuclear 
translocation for the release of DOX to be exploited [27]. Furthermore, ferritin nanoparticles have been used to stabilize lipophilic drugs, such as curcumin [74]. However, to date few studies have been published on this, probably because low drug hydro solubility strongly affects the encapsulation reaction.

Ferritin-based nanocages could be implemented for the delivery of radioisotopes increasing loading efficiency and improving pharmacokinetics. Hainfeld has developed ferritin cages with a payload of about $800{ }^{235} \mathrm{U}$ atoms/nanoparticle, able to kill surrounding tumor cells [75]. The same strategy has been suggested as being applicable with other isotopes currently used in clinics, such as ${ }^{90}$ yttrium and ${ }^{177}$ luthetium [3].

Finally, ferritin nanocages have been employed for siRNA or miRNA delivery. These short noncoding RNA molecules, have been strongly related to either cancer progression or resistance, suggesting that miRNA/siRNA-based therapy could be associated with standard treatment. Lee and coworkers have recently proposed a genetic variant of $\mathrm{H}$-ferritin designed to mediate targeted delivery and internalization of siRNA immobilized on the nanoparticle surfaces through charge-charge interaction [50]. In vitro results demonstrated the efficacy of the as-designed nanoparticle in targeting tumor cells and the nanoparticle-mediated intracellular delivery of an anti-red fluorescent protein (RFP) siRNA, which induced RFP suppression [50]. This result paves the way for future application of ferritin nanoparticles in gene silencing.

\subsection{Ferritin nanoparticles for in vivo imaging}

The plasticity of ferritin as a mineralization chamber for heavy atoms or complexes, and the possibility of modifying ferritin nanocages by protein engineering or by chemical reaction to insert probe molecules, are features that make ferritin an ideal device for imaging [53]. In particular, ferritins have found great application in magnetic resonance imaging (MRI) and optical [73] imaging (Figure 3). Indeed, MRI is a powerful diagnostic technique with wide involvement in tumor imaging, thanks to its high sensitivity and accuracy [55]. However, the currently used gadolinium-based contrast 
agents indistinctly enhance all highly vascularized tissues, and thus lack specificity for cancer cells resulting in a high rate of false positives. On the other hand, occult cancer micro-deposits may be not detected on MRI due to an insufficient spatial resolution, and oligometastatic disease could be misdiagnosed [76, 77]. Both endogenous and exogenous ferritins have demonstrated great utility in this area by overcoming these limitations. Ferritin nanoparticles loaded with magnetic species have been developed as MRI contrast agents for tumor imaging. Cao and coworkers have obtained a nanoparticle with transverse relaxivity $\mathrm{r}_{2}$ of $224 \mathrm{mM}^{-1} \mathrm{~s}^{-1}$, by synthesizing a single crystal of magnetite inside the ferritin cage [78]. Injection of such nanoparticles in MDA-231 tumor-bearing mice caused a drop of the T2 signal due to TfR1-dependent tumor accumulation [78]. Moreover, iron nanoparticles have been produced into ferritin cages, and optimizing strategies have been developed by Uchida et al. by simply adjusting the extent of Fe loading [79]. The increased amount of iron in the reaction mixture determines an increase in the core size of iron nanoparticles encapsulated into ferritin, which is directly related to $\mathrm{T} 2$ contrast power $[79,80]$. Other types of MRI-detectable nanoparticles have been produced using the ferritin cavity as a reaction chamber. Five nm Gd nanoparticles have been produced inside ferritins, obtaining nanoparticles with longitudinal and transverse relaxivity from 10 to 70 times higher than commercially available Gd-chelates [81]. Mn-coupled ferritin-based MRI contrast agent, obtained by reduction of $\beta-\mathrm{MnOOH}$, has been reported by Kalman and coworkers. This nanoparticle contains up to $300-400 \mathrm{Mn}(\mathrm{II})$ ions and an $\mathrm{r}_{1}$ relaxivity ranging between $4000-7000 \mathrm{~s}^{-1}$ [82]. Aime et al. exploited a pH-mediated ferritin disassembly to load about 8-10 GdHPDO3A/nanoparticle, obtaining a $\mathrm{r}_{1}$ relaxivity of $80 \mathrm{mM}^{-1} \mathrm{~s}^{-1}$ [83]. Upon modification with C3d, a peptide that specifically recognizes vessel endothelium, Gd-nanoparticles showed a 30\% signal increase in tumor in a mouse model [53].

Ferritin nanoparticles can also be conjugated with dye molecules and find application as optical imaging probes in imaging-guided surgery for cancer [84]. Li et al. employed a ferritin H-chain genetically fused with epidermal growth factor (EGF), and subsequently labeled Cys residues with Alexa Fluor 750, for targeting EGFR-overexpressing breast cancer cells in mice [85]. Besides, Lin et 
al. developed a Cy5.5-labelled ferritin by reacting the dye with the protein's primary amine. Then, using the pH-disassembly procedure, the Cy5.5-labelled ferritin monomers were mixed with RGDbearing ferritin monomers. The resulting hybrid ferritin, which displays on the surface both the Cy5.5 dye and the RGD peptide, has been injected into U87MG tumor-bearing mice demonstrating good tumor accumulation [22]. In another study, Lin and coworkers mixed monomers of ferritin conjugated with the Cy5.5-GPLGVRG peptide or with the black hole quencher-3 (BHQ-3), obtaining a hybrid nanoparticle that emits fluorescence only in a metalloproteinase rich environment, such as that found in tumors [43]. This nanoparticle was further implemented through the encapsulation of ${ }^{64} \mathrm{Cu}, \mathrm{a}$ radioisotope commonly used in positron emission tomography (PET), thus obtaining a ferritin platform for multimodal imaging (Figure 5) [22]. Combining optical and nanotargeted strategies could improve and refine intraoperative imaging, to properly excise a tumor lesion with adequate margins, and provide targeted diagnostic tools for cancer follow up.

\subsection{Ferritin nanoparticles in photothermal therapy}

Thanks to its high biocompatibility, low immunogenicity and good pharmacokinetics profile ferritin is useful in photothermal therapy (PTT) [86]. PTT employs photothermal agents, which absorb the irradiation energy of an optical laser and convert it into heat for killing cancer cells. Indeed, most of the photothermal agents show high immunogenicity, non-biodegradability, long term toxicity and poor pharmacokinetics, which strongly affect their clinical application [87, 88]. Haung et al. have reported the development of a near infra-red (NIR)-loaded ferritin, which displayed strong absorbance in the NIR region for photoacustic/fluorescence multimodal imaging-guided PTT $[89,90]$. The as-designed ferritin nanovector exhibited in vivo high PTT efficacy and low systemic toxicity in comparison to the free dye [90]. Another kind of ferritin nanoparticle has been developed by the Ceci group as a platform for hyperthermia. They functionalized the ferritin cage with the melanoma targeting peptide and used it as a mineralization chamber for the synthesis of cobalt-doped ferrite nanoparticles. The assynthesized nanoparticles were uniform in size $(6-7 \mathrm{~nm})$ and morphology (spherical). Moreover, they 
displayed an in vitro hyperthermic efficacy inversely related to the amount of Co used for the doping [45]. Altogether, the reported data suggest that ferritin nanocages could be a promising vector for photothermal therapy, although further studies have to be performed to better investigate ferritin's potential in this field.

\section{Conclusions and future perspectives}

So far, nanotechnology has emerged as promising frontier in cancer treatment. Super-paramagnetic iron oxide nanoparticles (SPIONs) are being tested in clinical trials as magnetic contrast agents for MRI and for intraoperative sentinel node identification during breast cancer surgery [91, 92]. Liposomes have been already established in clinical practice for improving bioavailability and reducing toxicity profile of some excellent cytotoxic drugs associated with severe cardiotoxicity, such as anthracyclines [93]. Nanoformulated albumin-bound paclitaxel has been notoriously introduced in clinical management of various types of cancer with encouraging results in terms of anticancer efficacy [94]. However, these basic nanoparticles lack a specific method of cancer targeting, and despite their benefit in reducing side effects of cytotoxic drugs in clinical trials, no substantial improvement in long-term outcomes has been documented [95]. In this context, ferritin nanocages appear to be powerful and fascinating tools for both imaging and therapeutic purposes, in particular considering that ferritin is a protein normally present in physiological systems.

Different strategies of loading ferritin with drugs, molecules and metals have been successfully explored; nevertheless, some aspects particularly regarding their kinetic release from the nanovector still need to be investigated in detail. Much work has already been done to increase the types of molecules encapsulated, particularly in the case of non-metal-containing drugs, which include the majority of chemotherapeutics. However, a few questions remain: (1) the fate of ferritin and its derivatives after systemic injection and (2) the possibility to suppress ferritin uptake in off-target organs and/or sequestration by the reticulo-endothelial system, and thereby (3) the hope to extend a drug's half-life by modifying the ferritin surface with stealth moieties. Some research groups have 
taken advantage of the ability of $\mathrm{H}$-ferritin to specifically recognize TfR1 [33], a receptor expressed on the surface of many types of cancer cells [41]. Other groups have chemically or genetically inserted targeting motifs onto the ferritin surface, to improve tumor homing [42-54]. This strategy has been demonstrated to be very promising, since targeted therapies are probably the key for cancer treatment [96]. Specific targeting of cancer cell receptors enhances anticancer activity by selective inhibition of the underlying cellular pathways, and mediates a selective release of cytotoxic drugs. However, despite the fact that surface modification of ferritin imparts target specificity, it is not clear whether or not these modifications alter the nanoparticle's immunogenicity. Another aspect which should not be underestimated is the possibility of combination therapy. Encapsulation of various drugs into the same nanocage would provide contemporary multiple anticancer activities towards various cancer survival pathways. Finally, the intrinsic capability of ferritin nanocages to undergo nuclear translocation can be exploited to design a novel class of smart nanodrugs, which could act as "Trojan horses", by releasing chemotherapy into the nucleus of cancer cells, thus strongly improving their cytotoxic activity. At present, unfunctionalized DOX-loaded ferritin represents the most extensively investigated of the ferritin-based nanoparticles, and several in vitro and in vivo studies have demonstrated it to be successful. However, such nanoparticles are currently not used in clinical practice, and further research is required before clinical translation. Ferritin has also found an intriguing application in the field of in vivo imaging. Particularly, ferritin-based contrast agents for MRI have been developed, providing an imaging platform with increased tumor accumulation in comparison to the contrast agents currently used in clinical practice. However, toxicity, biodistribution and clearance of these nanocompounds needs to be more clearly understood before their clinical translation. Overall, ferritin nanocages are promising nano-platforms for imaging and therapy of cancer. Some issues still need to be thoroughly investigated, but many significant results have already been obtained. Physiological features and the bioengineering versatility of ferritin-based nanocages make their translation from bench to bedside a reasonable possibility. Moreover, the combination of imaging and therapeutic 
functionality into ferritin nanocages seems to be the most promising and fascinating frontier in cancer theranostics.

\section{Acknowledgements}

The research was supported by Fondazione Regionale per la Ricerca Biomedica (NANODRUG platform project). FRRB supported S.M, L.F. and M.T. We thank Chiara SRL and E. Fezzuoglio for figures and graphical abstract.

\section{FIGURES AND TABLES}

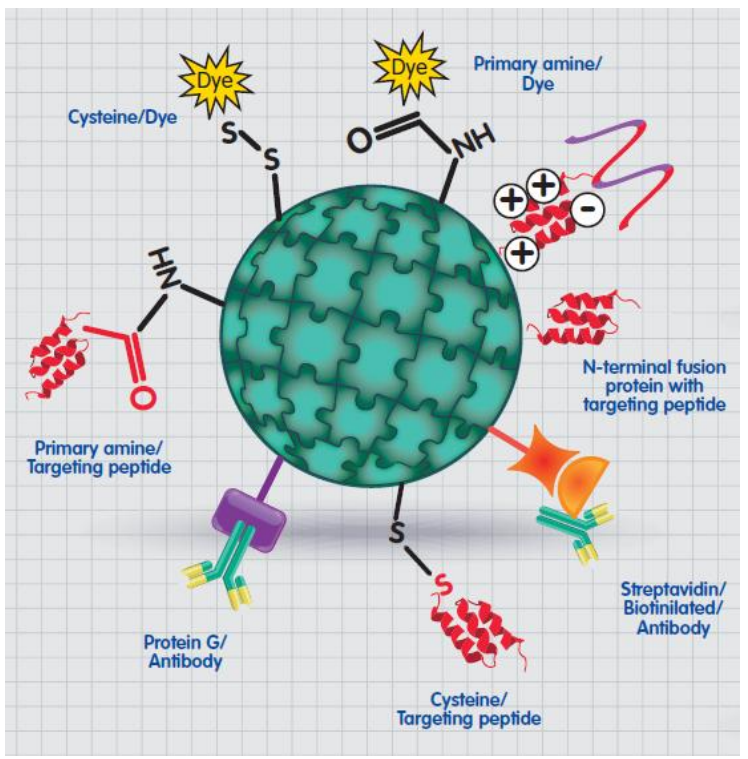

Figure 1. Schematic representation of strategies adopted to provide surface functionalization of ferritin with targeting peptides, antibodies, siRNA and fluorescent dyes.

Table 1. Main application prospects of ferritin nanocages in cancer diagnosis and treatment.

\begin{tabular}{|l|l|l|l|}
\hline Loaded with... & Functionalized with... & Application & Ref. number \\
\hline Cisplatin & - & Chemotherapy & $68,69,70$ \\
\hline Cisplatin & $\begin{array}{l}\text { antibody against the } \\
\text { melanoma antigen CSPG4 }\end{array}$ & Chemotherapy & 42 \\
\hline Doxorubicin & RGD peptide & Chemotherapy & 47 \\
\hline Doxorubicin & - & Chemotherapy & $27,72,73,75,30$ \\
\hline Curcumin & - & Therapy & 74 \\
\hline${ }^{235} \mathrm{U}$ & - & Radionuclide Therapy & 75 \\
\hline- & $\begin{array}{l}\text { anti-red fluorescent protein } \\
\text { (RFP) siRNA }\end{array}$ & RNA interference Therapy & 50 \\
\hline Magnetite crystal & & MR Imaging & $78,79,80$ \\
\hline Gadolinium & & MR Imaging & 81,83 \\
\hline
\end{tabular}




\begin{tabular}{|l|l|l|l|}
\hline Mn(II) & \multicolumn{1}{|l|}{} & MR Imaging & 82 \\
\hline Gadolinium & C3d & MR Imaging & 53 \\
\hline- & $\begin{array}{l}\text { EGF } \\
\text { Alexa Fluor 750 }\end{array}$ & Fluorescence Imaging & 85 \\
\hline- & $\begin{array}{l}\text { RGD peptide } \\
\text { Cy5.5 }\end{array}$ & Fluorescence Imaging & 22 \\
\hline- & $\begin{array}{l}\text { Cy5.5 } \\
\text { GPLGVRG peptide } \\
\text { black hole quencher-3 } \\
\text { (BHQ-3) } \\
\text { CGD peptide }\end{array}$ & Fluorescence Imaging & \\
\hline${ }^{64} \mathrm{Cu}$ & - & Positron Emission Tomography & 22 \\
\hline NIR & $\begin{array}{l}\text { Melanoma targeting peptide } \\
\text { (MSH) }\end{array}$ & Photothermal Therapy & 90,91 \\
\hline $\begin{array}{l}\text { Cobalt-doped ferrite } \\
\text { nanoparticles }\end{array}$ & Magnetic Fluid Hyperthermia & 45 \\
\hline
\end{tabular}

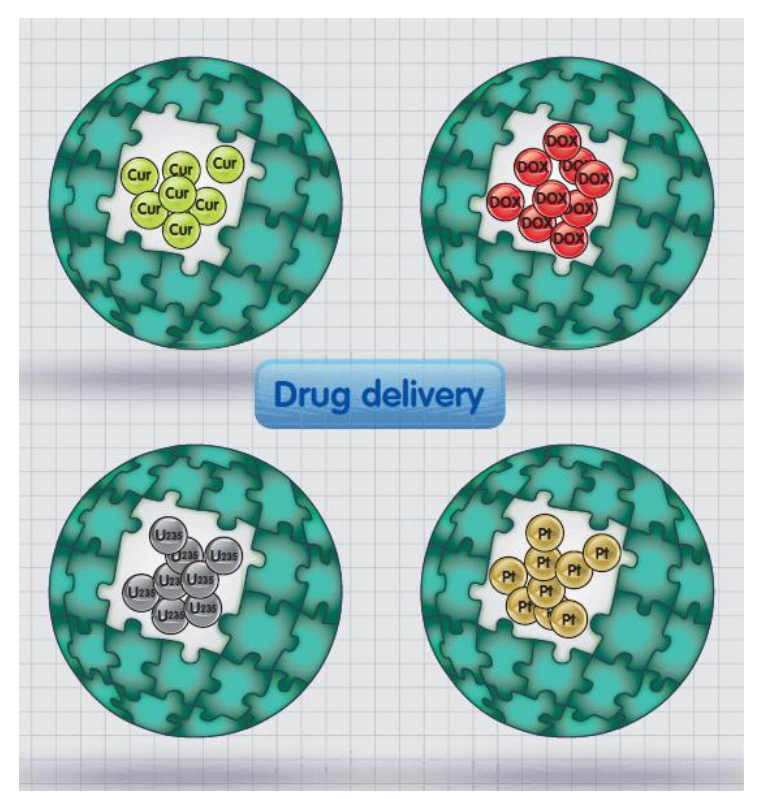

Figure 2. Schematic representation of ferritin developed for drug delivery to cancer. 
Figure 3. Schematic representation of ferritin developed for cancer imaging.

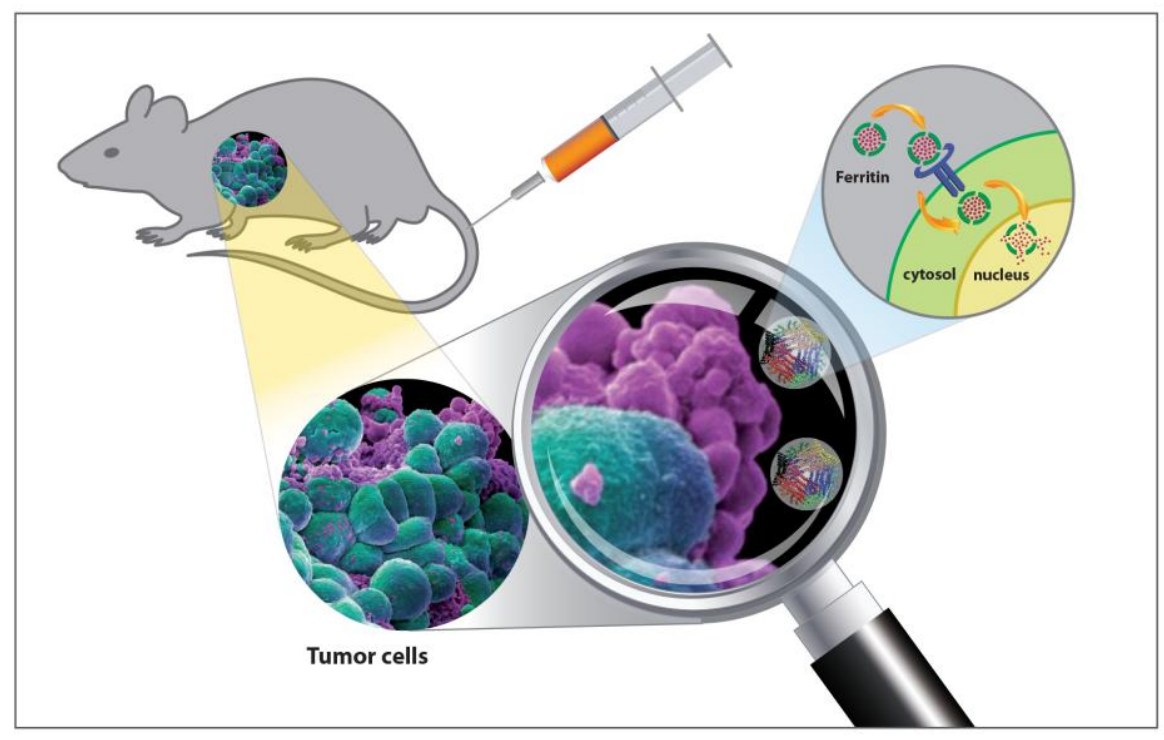

Figure 4. Schematic representation of in vivo drug delivery of ferritin nanoparticles.

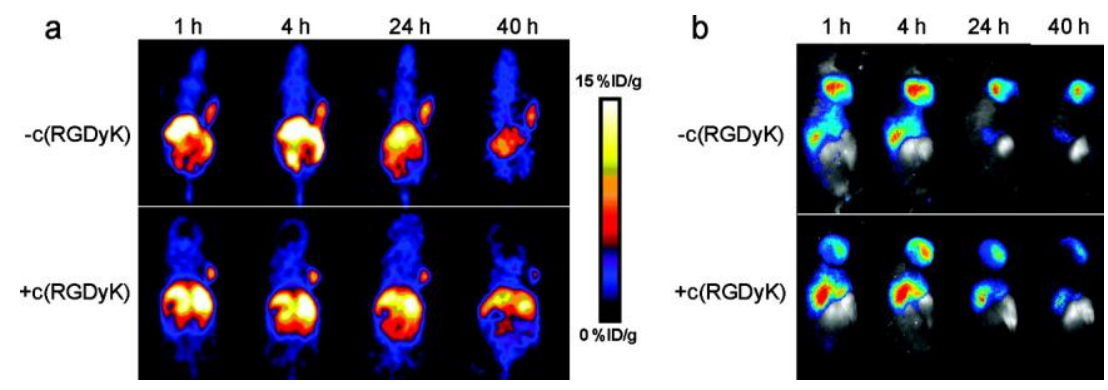


Figure 5. In vivo imaging with ferritin nanoparticles. In vivo images of (a) positron emission tomography (PET) and (b) near-infrared fluorescence images after administration of ferritin nanocages. 30 min before ferritin probe administration, mice were injected with a blocking dose of $\mathrm{c}(\mathrm{RGDyK})$ to demonstrate target specificity. (Reprinted with permission from Ref 22. Copyright 2011 American Chemical Society).

\section{References}

[1] Stewart B. W., Wild C. P. World cancer report 2014/Edited by Bernard W. Stewart and Christopher P. Wild, International Agency for Research on Cancer, Lyon, 2014.

[2] Colombo M, Corsi F, Mazzantini E, Mazzucchelli S, Marasso C, Occhipinti E, Polito L, Prosperi D, Ronchi S, Verderio P. HER2 targeting as a two-sided strategy for breast cancer diagnosis and treatment: outlook and recent implications in nanomedical approaches. Pharm. Res. 2010; 62: 150-165. [3] Maham A, Tang Z, Wu H, Wang J, LinY. Protein-based nanomedicine platforms for drug delivery. Small 2009; 5: 1706-1721.

[4] Peer D, Karp JM, Hong S, Farokhzad OC, Margalit R, Langer R. Nanocarriers as an emerging platform for cancer therapy. Nat Nanotechnol 2007; 2: 751-760.

[5] Mok H, Zhang M. Superparamagnetic iron oxide nanoparticle-based delivery systems for biotherapeutics. Expert Opin Drug Deliv 2013; 10: 73-87.

[6] Stanley S. Biological nanoparticles and their influence on organisms. Current Opinion in Biotechnology 2014; 28: 69-74.

[7] De Wong WH, Borm PJ. Drug delivery and nanoparticles: applications and hazards. Int.J. Nanomedicine 2008; 3: 133-149.

[8] Lefevre CT, Bazylinski DA. Ecology, diversity and evolution of magnetotactic bacteria. Microbiol Mol Biol Rev 2013; 77:497-526.

[9] Arakaki A, Nakazawa H, Nemoto M, Mori T, Matsunaga T. Formation of magnetite by bacteria and its application. J R Soc Interface 2008; 5:977-999. 
[10] Lang C, Schuler D, Faivre D. Synthesis of magnetite nanoparticles for bio- and nanotechnology: genetic engineering and biomimetics of bacterial magnetosomes. Macromol Biosci 2007; 7:144-151.

[11]] Jonas A, Phillips MC. Lipoprotein structure. In Biochemistry of Lipids, Lipoproteins and Membranes. Edited by Vance DE, Vance JE. Amsterdam: Elsevier Science; 2008:485-506.

[12] Ryan RO. Nanobiotechnology applications of reconstituted high density lipoprotein. J Nanobiotechnol 2010; 8:28.

[13] Vlassov AV, Magdaleno S, Setterquist R, Conrad R. Exosomes: current knowledge of their composition, biological functions, and diagnostic and therapeutic potentials. Biochim Biophys Acta 2012; 1820:940-948.

[14] Suntres Z, Smith M, Momen-Heravi F, Hu J, Zhang X, Wu Y, Zhu H, Wang J, Zhou J, Kuo W. Therapeutic uses of exosomes. Exosomes Microvesicles 2013; 1 http://dx.doi.org/10.5772/56522.

[15] Varez-Erviti L, Seow Y, Yin H, Betts C, Lakhal S, Wood MJ. Delivery of siRNA to the mouse brain by systemic injection of targeted exosomes. Nat. Biotechnol. 2011; 29:341-345.

[16] Jang SC, Kim OY, Yoon CM, Choi DS, Roh TY, Park J, Nilsson J, Lotvall J, Kim YK, Gho YS. Bioinspired exosome-mimetic nanovesicles for targeted delivery of chemotherapeutics to malignant tumors. ACS Nano 2013; 7(9):7698-7710.

[17] Zeltins A. Construction and characterization of virus-like particles: a review. Mol. Biotechnol. 2013; 53:92-107.

[18] Munro HN, Linder MC. Ferritin: structure, biosynthesis, and role in iron metabolism. Physiol. Rev. 1978; 58:317-96.

[19] Zhen Z, Tang W, Guo C, Chen H, Lin X, Liu G, Fei B, Chen X, Xu B, Xie J. Ferritin nanocages to encapsulate and deliver photosensitizers for efficient photodynamic therapy against cancer. ACS Nano 2013; 7:6988-96.

[20] Sun C, Yang H, Yuan Y, Tian X, Wang L, Guo Y, Xu L, Lei J, Gao N, Anderson GJ, Liang XJ, Chen C, Zhao Y, Nie G. Controlling assembly of paired gold clusters within apoferritin nanoreactor for in vivo kidney targeting and biomedical imaging. J. Am. Chem. Soc. 2011; 133: 8617-24. 
[21] Hainfeld JF. Uranium-loaded apoferritin with antibodies attached - molecular design for uranium neutron-capture therapy. Proc. Natl. Acad. Sci. USA 1992; 89:11064-8 15.

[22] Lin X, Xie J, Niu G, Zhang F, Gao H, Yang M, Quan Q, Aronova MA, Zhang G, Lee S, Leapman R, Chen X. Chimeric ferritin nanocages for multiple function loading and multimodal imaging. Nano Lett. $2011 ; 11: 814-19$.

[23] Zhen Z, Tang W, Chen H, Lin X, Todd T, Wang G, Cowger T, Chen X, Xie J. RGD-modified apoferritin nanoparticles for efficient drug delivery to tumors. ACS Nano 2013; 7:4830-7.

[24] Laufberger V. Sur la cristallisation de la ferritine. Bull. Soc. Chim. Biol. 1937; 19:1575-1582.

[25] Arosio P., Ingrassia R. Cavdini P. Ferritins: a family of molecules for iron storage, antioxidation and more. Biochimica et Biophysica Acta 2009; 1790: 589-599.

[26] Charsteen ND. Ferritin. Uptake, storage and release of iron. Met. Ions Biol.Syst. 1998; 35:479514.

[27] Bellini M, Mazzucchelli S, Galbiati E, Sommaruga S, Fiandra L, Truffi M, Rizzuto MA, Colombo M, Tortora P, Corsi F, Prosperi D. Protein nanocages for self-triggered nuclear delivery of DNAtargeted chemotherapeutics in Cancer Cells. J. Controlled Release 2014; 196: 184-196.

[28] Thompson KJ, Fried MG, Ye Z, Boyer P, Connor JR. Regulation, mechanisms and proposed function of ferritin translocation to cell nuclei. J. Cell Sci. 2002; 115: 2165-2177.

[29] Douglas T, Ripoll DR. Calculated electrostatic gradients in recombinant human H-chain ferritin. Protein Sci. 1998; 7: 1083-1091.

[30] Zhang L, Li L, Di Penta A, Carmona U, Yang F, Schops R, Brandsch M, Zugaza JL, Knez M. HChain Ferritin: A Natural Nuclei Targeting and Bioactive Delivery Nanovector. Adv. Healthcare Mater. 2015; 4: 1305-1310.

[31] Surguladze N, Patton S, Cozzi A, Fried MG, Connor JR. Characterization of nuclear ferritin and mechanism of translocation. Biochem. J. 2005; 388: 731-740.

[32] Kim M, Rho Y, Jin KZ, Ahn B, Jung S, Kim H, Ree M. pH-dependent structures of ferritin and apoferritin in solution: disassembly and reassembly. Biomacromolecules 2011; 12: 1629-1640. 
[33] Li L, Fang CJ, Ryan JC, Niemil EC, Lebrón JA, Björkman PJ, Arase H, Torti FM, Torti SV, Nakamura MC, Seaman WE. Binding and uptake of H-ferritin are mediated by human transferring receptor-1. Proc. Natl. Acad. Sci. U. S. A. 2010; 107: 3505-3510.

[34] Fan K, Gao L, Yan X. WIREs Nanomed Nanobiotechnol 2013; 5: 287-298.

[35] Chen TT, Chung DH, Allen CD, Torti SV, Torti FM, Cyster, JG. TIM-2 is expressed on B cells and in liver and kidney and is a receptor for H-ferritin endocytosis. J Exp Med 2005; 202: 955-965.

[36] Han J, Seaman WE, Di X, Wang W, Willingham M, Torti FM, Torti SV. Iron uptake mediated by binding of H-ferritin to the TIM-2 receptor in mouse cells. PLoS ONE 2011; 6(8): e23800.

[37] Todorich B, Zhang X, Slagle-Webb B, Seaman WE, Connor JR. Tim-2 is the receptor for Hferritin on oligodendrocytes. Journal of Neurochemistry 2008; 107: 1495-1505.

[38] Chen TT, Li L, Chung D-H, Allen CDC, Torti SV, Torti FM, Cyster JG, Chen C-Y, Brodsky FM, Niemi EC, Nakamura MC, Seaman WE, Daws MR. TIM-2 is expressed on B cells and in liver and kidney and is a receptor for H-ferritin endocytosis. J Exp Med. 2005; 202: 955-965

[39] Chen TT, Li L, Chung D-H, Allen CDC, Torti SV, Torti FM, Cyster JG, Chen C-Y, Brodsky FM, Niemi EC, Nakamura MC, Seaman WE, Daws MR. JEM 2005; 202: 655-965.

[40] Li JY, Paragas N, Ned RM, Qiu A, Viltard M, Leete T, Drexler IR, Chen X, Sanna-Cherchi S, Mohammed F, Williams D, Lin CS, Schmidt-Ott KM, Andrews NC, Barasch J. Scara5 is a ferritin receptor mediating non-transferrin iron delivery. Dev Cell 2009; 16: 35-46.

[41] Fan K, Cao C, Pan Y, Lu D, Yang D, Feng J, Song L, Liang M, Yan X. Magnetoferritin nanoparticles for targeting and visualizing tumour tissues. Nat. Nanotechnol. 2012; 7: 459-464.

[42] Falvo E, Tremante E, Fraioli R, Leonetti C, Zamparelli C, Boffi A, Morea V, Ceci P, Giacomini P. Antibody-drug conjugates: targeting melanoma with cisplatin encapsulated in protein-cage nanoparticles based on human ferritin. Nanoscale 2013; 5: 12278-12285.

[43] Lin X, Xie J, Zhu L, Lee S, Niu G, Ma Y, Kim K Chen X. Hybrid ferritin nanoparticles as activatable probes for tumor imaging. Angew. Chem. Int. Ed. 2011; 50: 1569-1572. 
[44] Kang YJ, Yang HJ, Jeon S, do Y, Hong SY, Kang S. Polyvalent display of monosaccharides on ferritin protein cage nanoparticles for the recognition and binding of ceel-surface lectins. Macromol. Biosci. 2014; 14: 619-625.

[45] Fantechi E, Innocenti C, Zanardelli M, Fittipaldi M, Falvo E, Carbo M, Shullani V, Di Cesare Mannelli L, Ghelardini C, Ferretti AM, Ponti A, Sangregorio C, Ceci P. A smart platform for hyperthermia application in cancer treatment: cobalt-doped ferrite nanoparticles mineralized in human ferritin cages. ACS Nano 2014; 8: 4705-4719.

[46] Uchida M, Willits DA, Muller K, Wills AF, Jackiw L, Jutila M, Young MJ, Porter AE, Douglas T. Intracellular distribution of macrophage targeting ferritin-iron oxide nanocomposite. Adv. Mater. $2009 ; 21: 458-462$.

[47] Zheng Z, Tang W, Chen H, Lin X, Todd T, Wang G, Cowger T, Chen X, Xie J. RGD-modified nanoparticles for efficient drug delivery to tumors. ACS Nano 2013; 7: 4830-4837.

[48] Vannucci L, Falvo E, Fornara M, Di Micco P,Benada O, Krizan J, Svoboda J,Hulikova-Capkova K, Morea V, Boffi A, Ceci P. Selective targeting of melanoma by PEG-masked protein-based multifunctional nanoparticles. Int J Nanomedicine. 2012; 7: 1489-1509.

[49] Lee J-H, Seo HS, Song JA, Kwon KC, Lee EJ Kim HJ, Lee EB, Cha YJ, Lee J. Proteinticle Engineering for Accurate 3D Diagnosis. ACS Nano 2013; 7: 10879-10886.

[50] Lee EJ, Lee SJ, Kang Y-S, Ryu JH, Kwon KC, Jo E, Yhee JY, Kwon IC, Kim K, Lee J. Engineered Proteinticles for targeted Delivery of siRNA to Cancer Cells. Adv. Funct. Mater. 2015; 25 : 1279-1286.

[51] Kanekiyo M, Wei C-J, Yassine HM, McTamney PM, BoyingtonJC, Whittle JRR,Rao SS, Kong W-P, Wang L, Nabel GJ. Self-assembling influenza nanoparticles vaccines elicit broadly neutralizing H1N1 antibodies. Nature 2013; 499: 102-106.

[52] Han J-A, Kang YJ, Shin C, Ra J-S, Shin H-H, Hong SY, Do Y, Kang S. Ferritin protein cage nanoparticles as versatile antigen delivery nanoplatforms for dendritic cell (DC)-based vaccine development. Nanomedicine: Nanotechnology, biology, and Medicine 2014; 10: 561-569. 
[53] Geninatti Crich S, Bussolati B, Tei L, Grange C, Esposito G, Lanzardo S, Camussi G, Aime S. Magnetic Resonance Visualization of Tumor Angiogenesis by Targeting Neural Cell Adhesion Molecules with the Highly Sensitive Gadolinium-Loaded Apoferritin Probe. Cancer Res. 2006; 66: 9196-9201.

[54] Hwang M, Lee J-W, Lee KE, Lee KH. Think modular: a Simple Apoferritin-Based platform for the Multifaceted Detection of Pancreatic Cancer. ACS Nano 2013; 9: 8167-8174.

[55] He D, Marles-Wright J. Ferritin family proteins and their use in bionanotechnology. New Biotechnology 2015; 32: 651-657.

[56] Yamashita I, Iwahori K, Kumagai S. Ferritin in the field of nanodevices. Biochimica et Biophysica Acta 2010; 1800: 846-857.

[57] Meldrum FC, Heywood BR, Mann S. Magnetoferritin: in vitro synthesis of a novel magnetic protein. Science 1992; 257: 522-523.

[58] Meldrum FC Douglas T, Lesi S, Arosio P, Mann S. Reconstitution of manganese oxide cores in horse spleen and recombinant ferritins. J. Inorg. Chem. 1995; 58: 59-68.

[59] Douglas T, Stark VT. Nanophase cobalt oxihydroxidemineral synthesis within the protein cage of ferritin. Inorg. Chem. 2000; 39: 1828-1830.

[60] Okuda M, Iwahori K, Yamashita I, Yoshimura H. Fabrication of Nickel and chromium nanoparticles using the protein cage of apoferritin. Biotech. Bioeng. 2003; 84: 187-193.

[61] Xing R, Wang X, Yan L, Zhang C, Tang Z, Wang X, Guo Z. Fabrication of water soluble and biocompatible CdSe nanoparticles in apoferritin with the aid of EDTA. Dalton Trans. 2009; 17101713.

[62] Yamashita I, Hayashi J, Hara M. Bio-template synthesis of uniform CdSe nanoparticles using cage-shaped Protein Apoferritin. Chem. Lett. 2004, 33: 1158-1159.

[63] Iwahori K, Yoshizawa K, Muraoka M, Yamashita I. Fabrication of ZnSe nanoparticles in the apoferritin cavity by designing a slow chemical reaction system. Inorg. Chem. 2005; 44: 6393-6400. 
[64] Iwahori K, Yamashita I. Fabrication of CdS nanoparticles in the bio-template, apoferritin cavity by a slow chemical reaction system. J. Phys. 2007; CS 61: 492-496.

[65] Iwahori K, Yamashita I. Size-controlled one-pot synthesis of fluorescent cadmium sulfide semiconductor nanoparticles in an apoferritin cavity. Nanotechnology 2008; 19: 495601.

[66] Jaaskelainen A, Soukka T, Lamminmaki T, Korpimaki T, Virta M. Biotechnology and Bioengineering 2009; 102: 1012-1024.

[67] Dominguez-Vera JM. Iron (III) complexation of Desferoxamine B encapsulated in apoferritin. J Inorg Biochem 2004; 75: 3145-3157.

[68] Yang Z, Wang X, Diao H, Zhang J, Li H, Sun H Guo Z. Encapsulation of platinum anticancer drugs by apoferritin. Chem. Commun. 2007; 33: 3453-3455.

[69] Xing R, Wang X, Zhang C, Zhang Y, Wang Q, Yang Z, GuoZ. Characterization and cellular uptake of platinum anticancer drugs encapsulated in apoferritin. Journal of Inorganic Biochemistry 2009; 103: 1039-1044.

[70] Ji H-T, Huang L, Huang H-Q. Construction of nanometer cisplatin core-ferritin (NCC-F) and proteomic analysis of gastric cancer cell apoptosis induced with cisplatin released from the NCC-F. J. Proteomics 2012; 75: 3145-3157.

[71] Maham A, Wu H, Wang J, Kang X, Zhang Y, Lin Y. Apoferritin-based nanomedicine platform for drug delivery: equilibrium binding study of daunomycin with DNA. J. Mater. Chem. 2011; 21: 8700-8708.

[72] Liang M, Fan K, Zhou M, Duan D, Zheng J, Yang D, Feng J, Yan X. H-ferritin-nanocaged doxorubicin nanoparticles specifically target and kill tumors with a single-dose injection. Proc. Natl. Acad. Sci. U S A. 2014; 111:14900-14905.

[73] Zhen Z, Tang W, Todd T, Xie J. Ferritins as nanoplatforms for imaging and drug delivery. Expert Opin. Drug Deliv. 2014; 11: 1913-1922.

[73] Kilic MA, Ozlu E, Calis S. A Novel Protein-Based Anticancer Drug Encapsulating Nanosphere: Apoferritin-Doxorubicin Complex. Journal of Biomedical Nanotechnology 2012; 8: 508-514. 
[74] Chen L, Bai G, Yang S, Yang R, Zhao G, Xu C, Leung W. Encapsulation of curcumin in recombinant human $\mathrm{H}$-chain ferritin increases its water-solubility and stability. Food Research International 2014; 62: 1147-1153.

[75] Hainfeld JF. Uranium-loaded apoferritin with antibodies attached-molecular design for uranium neutron-capture therapy. Proc. Natl. Acad. Sci. USA 1992; 89: 11064-11068.

[76] Plana MN, Carreira C, Muriel A, Chiva M, Abraira V, Emparanza JI, Bonfill $\mathrm{X}$, Zamora J. Magnetic resonance imaging in the preoperative assessment of patients with primary breast cancer: systematic review of diagnostic accuracy and meta-analysis. Eur Radiol. 2012; 22(1):26-38.

\section{[77] Millet I, Pages E, Hoa D, Merigeaud S, Curros Doyon F, Prat X, Taourel P.} Pearls and pitfalls in breast MRI. Br J Radiol. 2012; 85(1011):197-207.

[78] Cao C, Wang X, Cai Y, Sun L, Tian L, Wu H, He X, Lei H, Liu W, Chen G, Zhu R, Pan Y. Targeted In vivo Imaging of Microscopic Tumors with Ferritin-Based Nanoprobes Across Biological Barriers. Adv. Mater. 2014; 26: 2566-2571.

[79] Uchida M, Flenniken ML, Allen M, Willits DA, Crowley BE, Brumfield S, Willis AF, Jackiw L, Jutila M, Young MJ, Douglas T. Targeting of cancer cells with ferrimagnetic ferritin cage nanoparticles. J. Am. Chem. Soc. 2006; 128: 16626-16633.

[80] Cai Y, Cao C, He X, Yang C, Tian L, Zhu R, Pan Y. Enhanced magnetic resonance imaging and staining of cancer cells using ferromagnetic H-ferritin nanoparticles with increasing core size. Int. J. Nanomed. 2015; 10: 2619-2634.

[81] Sanchez P, Valero E, Galvez N, Domínguez-Vera JM, Marinone M, Poletti G, Corti M, Lascialfari A. MRI relaxation properties of water-soluble apoferritin-encapsulated gadolinium oxidehydroxide nanoparticles. Dalton Trans. 2009; 5: 800-804. 
[82] Kalman FK, Geninatti-Crich S, Aime S. Reduction/Dissolution of a beta-MnOOH nanophase in the ferritin cavity to yield a highly sensitive, biologically compatible magnetic resonance imaging agent. Angew. Chem. Int. Ed. Engl. 2010; 49: 612-615.

[83] Aime S, Frullano L, Geninatti-Crich S. Compartimentalization of a gadolinium complex in the apoferritin cavity: a route to obtain high relaxivity contrast agents for magnetic resonance imaging. Angew. Chem. Int. Ed. Engl. 2002; 114: 1059-1061.

[84] Chi C, Du Y, Ye J, Kou D, Qiu J, Wang J, Tian J, Chen X. Intraoperative imagingguided cancer surgery: from current fluorescence molecular imaging methods to future multimodality imaging technology. Theranostics. 2014; 4(11):1072-84.

[85] Li X, Qui L, Zhu P, Tao X, Imanaka T, Zhao J, Huang Y, Tu Y, Cao X. Epidermal Growth FactorFerritin H- Chain Protein Nanoparticles for Tumor Active Targeting. Small 2012; 8: 2505-2514.

[86] Kuo WS, Chang CN, Chang YT, Yang MH, Chien YH, Chen SJ, Yeh CS. Gold Nanorods in Photodynamic Therapy, as Hyperthermia Agents, and in Near-Infrared Optical Imaging. Angew. Chem. Int. Ed. 2010; 122: 2771-2775.

[87] Zha Z, Deng Z, Li Y, Li C, Wang J, Wang S, Qu E, Dai Z. Biocompatible polypyrrole nanoparticles as a novel organic photoacoustic contrast agent for deep tissue imaging. Nanoscale 2013; $5: 4462-7$.

[88] Fernandez-Fernandez A, Manchanda R, Lei T, Carvajal DA, Tang Y, Kazmi SZ, McGoron AJ. Comparative study of the optical and heat generation properties of IR820 and indocyanine green. Mol Imaging 2012; 11: 99-113.

[89] Gao FP, Lin YX, Li LL, Liu Y, Mayerhöffer U, Spenst P, Su JG, Li JY, Würthner F, Wang H. Supramolecular adducts of squaraine and protein for noninvasive tumor imaging and photothermal therapy in vivo. Biomaterials 2014; 35: 1004-14.

[90] Huang P, Rong P, Jia A, Yan X, Zhang MG, Lin J, Hu H, Wang Z, Yue X, Li W, Niu G, Zeng W, Wang W, Zhou K, Chen X. Dye-Loaded Ferritin Nanocages For Multimodal Imaging and Photothermal Therapy. Adv. Mater. 2014; 26: 6401-6408. 
[91] Bakhtiary Z, Saei AA, Hajipour MJ, Raoufi M, Vermesh O, Mahmoudi M.

Targeted superparamagnetic iron oxide nanoparticles for early detection of cancer: Possibilities and challenges. Nanomedicine. 2015. doi: 10.1016/j.nano.2015.10.019.

[92] Ahmed M, Anninga B, Goyal S, Young P, Pankhurst QA, Douek M; MagSNOLL Trialists Group. Magnetic sentinel node and occult lesion localization in breast cancer (MagSNOLL Trial). Br J Surg. 2015; 102(6): 646652.

[93] Tahover E, Patil YP, Gabizon AA. Emerging delivery systems to reduce doxorubicin cardiotoxicity and improve therapeutic index: focus on liposomes. Anticancer Drugs. 2015; 26(3): 241-258.

[94] $\mathrm{Yu}$ X, Jin C. Application of albumin-based nanoparticles in the management of cancer. J Mater Sci Mater Med. 2016; 27(1): 4. doi: 10.1007/s10856-015-5618-9.

[95] Xing M, Yan F, Yu S, Shen P. Efficacy and Cardiotoxicity of Liposomal Doxorubicin-Based Chemotherapy in Advanced Breast Cancer: A MetaAnalysis of Ten Randomized Controlled Trials. PLoS One. 2015; 10(7): e0133569. 
[96] Gianni L. The future of targeted therapy: combining novel agents.

Oncology 2002; 63:47-56. 